\title{
Beyin tümörlü hastaların radyoterapi retrospektif değerlendirilmesi
}

\author{
Patients with brain tumors were evaluated retrospectively after radiotherapy \\ Birsen Yücel*, Ebru Atasever Akkaş, Eda Erdiş, Yıllar Okur, Mehmet Fuat Eren, \\ Nalan Babacan, Turgut Kaçan, Saadettin Kılıçkap
}

Radyasyon Onkolojisi Anabilim Dalı (Yrd. Doç. Dr. B. Yücel, Yrd. Doç. Dr. M. F. Eren), Tıbbi Onkoloji Bilim Dalı (Yrd. Doç. Dr. N. Babacan, Dr. T. Kaçan, Doç. Dr. S. Kılıçkap), Cumhuriyet Üniversitesi Tıp Fakültesi, TR-58140 Sivas, Radyasyon Onkolojisi Kliniği (Dr. E. A. Akkaş), Sivas Numune Hastanesi, TR-58040 Sivas, Radyasyon Onkolojisi Kliniği (Dr. E. Erdiş), Antakya Devlet Hastanesi, TR-31040 Antakya, Radyasyon Onkolojisi Kliniği (Dr. Y. Okur), Ankara Numune Hastanesi TR- 06100 Ankara

\begin{abstract}
Özet
Amaç. Bu çalışmada, adjuvan radyoterapi veya kemoradyoterapi ile tedavi edilen beyin tümörlü hastaların sağkalım analizi, tedavi yan etkileri ve sağkalımı etkileyen prognostik faktörlerin incelemesi amaçlandı. Yöntem. Çalışmada Cumhuriyet Üniversitesi Tıp Fakültesi Araştırma ve Uygulama Hastanesi Onkoloji Merkezinde takip edilen 76 beyin tümörlü hasta verileri retrospektif olarak incelendi. Bulgular. Elli bir (\%67) erkek, 25 (\%33) kadın toplam 76 hasta çalışmaya dahil edildi. Histopatolojik olarak: 18'inde (\%24) düşük gradeli glial tümör, 17'sinde (\%22) yüksek gradeli glial tümör, 33'ünde (\%44) glioblastoma multiforme, 4'ünde (\%5) hipofiz adenomu ve 4 'ünde (\%5) medullablastom bulunmaktaydı. Ortanca takip süresi 16 ay (1-199 ay) idi. İki yıllık genel sağkalım ve 2 yıllık hastalıksız sağkalım: düşük gradeli glial tümörlerde sırasıyla \%83 ve $\% 83$, yüksek gradeli glial tümörlerde $\% 46$ ve $\% 40$, glioblastoma multiforme hastalarında $\% 28$ ve $\% 24$ olarak tespit edildi. Tek değişkenli analizde hastaların genel sağkalımını, histopatoloji $(<0,001)$, yaş $(\leq 50$ ve $>50, p<0,001)$, grade (p:0,003), Ki-67 değeri $(\leq 10$ ve $>10, p: 0,016)$, Eastern Cooperative Oncology Group performans durumu (p:0,006) ve cerrahi (biopsi ile total rezeksiyon karşılaştırıldığında p:0,017) etkiledi. Çok değişkenli analizde ise grade (p: 0,013), yaş (p:0,025) ve Eastern Cooperative Oncology Group performans durumu $(\mathrm{p}<0,001)$ sağkalımı bağımsız olarak etkileyen prognostik faktörlerdi. Akut yan etki olarak en sık $51(\% 67)$ hastada baş ağrısı, $32(\% 42)$ hastada bulantı-kusma görüldü. Radyoterapi nekrozu 3 (\%5) hastada da teşhis edildi. Sonuç. Bu çalışmada, glioblastoma multiforme ve yüksek gradeli glial tümörlerde genel ve hastalıksız sağkalım düşük gradeli glial tümörler hariç literatür ile benzer sonuçlar göstermektedir. Bu hasta grubunun en önemli prognostik faktörleri ise grade, yaş ve Eastern Cooperative Oncology Group performans durumu olarak belirlendi.
\end{abstract}

Anahtar sözcükler: Beyin tümörü, sağkalım, prognoz

\begin{abstract}
Aim: The purpose of this study is to review survival analysis, side effects and prognostic factors in patients with brain tumors who were treated with adjuvant radiotherapy or chemoradiotherapy. Methods. In this study, we retrospectively evaluated data of 76 patients with brain tumors followed-up at Cumhuriyet University Medical Faculty of Oncology Centre. Results. This study analysed data belonging to 76 patients; $51(67 \%)$ men, and $25(33 \%)$ women. There were histopathologicly low-grade gliomas in 18 (\%24) patients, high-grade gliomas in $17(\% 22)$ patients, glioblastoma multiforme in 33 (\%44), pituitary adenomas in 4 (\%5) patients and medullablastoma in $4(\% 5)$ patients. The median follow-up was 16 months (range, 1-199). The 2year overall and disease-free survival were $83 \%$ and $83 \%$ at low-grade gliomas, $46 \%$ and $40 \%$ at high-grade gliomas, $28 \%$ ve $24 \%$ at glioblastoma multiforme, respectively. The factors that determined survival were histopathology ( $<<0,001)$, age $(\leq 50$ and $>50, p<0,001)$, grade ( $\mathrm{p}: 0,003)$, Ki-67 value ( $\leq 10$ and $>10$, p: 0,016), Eastern Cooperative Oncology Group performance status (p: 0,006) and surgery (biopsy vs total resection p: 0,017). Eastern Cooperative Oncology Group performance status $(\mathrm{p}<0,001)$ and histopathology ( $\mathrm{p}$ : 0,022) were determined as indepent prognostic factors that affect survival after multivariate analysis. The most acute side effects were
\end{abstract}


headaches in $51(\% 67)$ patients, nausea and vomiting in $32(\% 42)$ patients. Radionecrosis was diagnosed in $3(\% 5)$ patients. Conclusion. It was showed that the overall survival and disease-free survival complied with the literature in high-grade gliomas and glioblastoma multiforme except low-grade gliomas. The most prognostic factors were grade, age and Eastern Cooperative Oncology Group performance status in this patients.

Keywords: Brain tumors, survival, prognosis

Geliş tarihi/Received: 22 Mayıs 2012; Kabul tarihi/Accepted: 03 Eylül 2012

\section{*İletişim adresi:}

Dr. Birsen Yücel, Radyasyon Onkolojisi Anabilim Dalı, Cumhuriyet Üniversitesi Tıp Fakültesi, TR-58140 Sivas, E-posta: yucelbirsen@yahoo.com

\section{Giriş}

Beyin tümörleri, tüm kanserler içinde görülme sıklığ1 \%1,4'tür ve kansere bağlı ölüm nedenlerinin arasında küçük bir orana $(\% 2,4)$ sahiptir. Ancak bu kanserlerin çoğunun beyin fonksiyonlarını bozması nedeniyle benign tümörlerde bile fatal seyredebilmektedir [1].

Beyin tümörlerinin büyük çoğunluğunu oluşturan glial tümörler nöroektodermden gelişir ve nöroglial orjinlerine göre: astrositom, oligodendrogliom ve epandimom olarak ayrilır. Beyin tümörlerinin \%82'sinin astrositom, anaplastik astrositom ve glioblastoma multiforme, \%14'ünün de medullablastom, oligodendrogliom, oligoastrositom, ependimom, meninjiom ve pilositik astrositom oluşturmaktadır [2].

Menenjiom ve neurinoma dışında görülme sıklığı erkeklerde daha fazladır [3]. Erişkinlerde sıklıkla supratentorial yerleşimlidir. Başlangıç semptomları tümörün yerleşim yerine göre değişmektedir. Baş ağrısı, konvüzyon, bulantı ve kusma en sık görülen semptomlarıdır [2]. Baş ağrısı genellikle hızlı büyüme nedeniyle kafa içi basıncının artmasına neden olan yüksek gradeli tümörde görülür. Konvüzyon ise daha sıkla düşük gradeli tümörlerde rastlanmaktadır [4].

The Surveillance, Epidemiology, and End Results (SEER) Program 1979-1993 verilerine göre 2 yıllık sağkalım pilositik astrositomda $\% 90$, anaplastik astrositomda $\% 45$, glioblastoma multiformede $\% 9$, medulloblastomada $\% 70$, oligodentrogliomada $\% 79$, ependimomada $\% 80$ olarak raporlanmıştır [5].

Düşük gradeli tümörlerde yapılabilirse, total tümör rezeksiyonu küratif tedavi olmaktadır. Yüksek gradeli tümörlerde cerrahi sonrası tüm hastalarda nüksü azaltmak için radyoterapi, son zamanlarda da temozolomide ile birlikte eş zamanlı kemoradyoterapi uygulamaları yer almaktadır. Özellikle glioblastoma multiformeli hastalarda temozolomide ile birlikte kemoradyoterapi hastaların sağkalımında düzelme sağlamıştır [6]. Histopatoloji, yaş ve hastanın performans durumu klinik olarak en önemli prognostik faktörlerdir [2].

Bu çalışmada, beyin tümörü nedeniyle başvuran hastaların klinikopatolojik özelliklerinin belirlenmesi, hastaların sağkalım analizi, tedavi yan etkileri ve sağkalımı etkileyen prognostik faktörlerin belirlenmesi amaçlanmıştır.

\section{Gereç ve yöntem}

Cumhuriyet Üniversitesi Tıp Fakültesi Eğitim Araştırma ve Uygulama Hastanesi Radyasyon Onkolojisi Anabilim Dalına 2006-2011 tarihleri arasında başvuran ve beyin tümörü tanısı ile radyoterapi yada kemoradyoterapi uygulanan hastalara ait demografik, klinik ve histopatolojik veriler, hasta dosya ve hastane kayıtları incelenerek elde edildi. Tüm hastalar için İl Nüfus Müdürlügünden izin alınarak kimlik sorgulama sisteminden 
hastaların yaşayıp yaşamadıkları öğrenilerek kaydedildi.

Hastaların performans durumu hasta başvurusunda Eastern Cooperative Oncology Group (ECOG) skorlama sistemine göre değerlendirildi.

Düşük gradeli glial tümörlerde, cerrahi uygulanamayan veya subtotal eksizyon yapılmış hastalarda, yüksek gradeli glial tümör ve glioblastome multiformeli hastalarda ise biopsi veya cerrahi sonrası tüm hastalara radyoterapi uygulandı. Radyoterapi planlamasında Eclipse v.8.6 (Varian Medical Systems, Inc. Palo Alto, CA) planlama programı kullanıldı. Hastaların tedavi volümleri: GTV1 (gross target volüm) magnetik rezonansda T2 sekanslarda ödem ile beraber görünen tümör ile oluşturulurken GTV2 (boost alanı için) sadece görünen tümör işaretlendi. CTV (klinik target volüm) GTV'ye yüksek gradeli tümörlerde $2 \mathrm{~cm}$, düşük gradeli tümörlerde ise $1,5 \mathrm{~cm}$ verilerek oluşturuldu. PTV (planlanan target volum) CTV'ye $0,5 \mathrm{~cm}$ marjin ile tedaviye alınd. Radyoterapi $200 \mathrm{cGy}$ günlük fraksiyon ile düşük gradeli glial tümörlerde toplam 27 fraksiyon (54 Gy), glioblastoma multiforme ve yüksek gradeli glial tümörlerde 30 fraksiyon (60 Gy), 6 MV foton enerjisi ile linac cihazında (Varian Medical Systems, Inc. Palo Alto, CA) uyguland. Ayrıca yüksek gradeli glial tümör ve glioblastoma multiformeli hastalarda temozolomide ( $75 \mathrm{mg} / \mathrm{m}^{2} /$ gün) radyoterapi ile eş zamanlı (kemoradyoterapi) uygulandı. Resim 1 ve 2 'de radyoterapi tedavi planı ve DVH (doz volüm histogramı) görülmektedir.

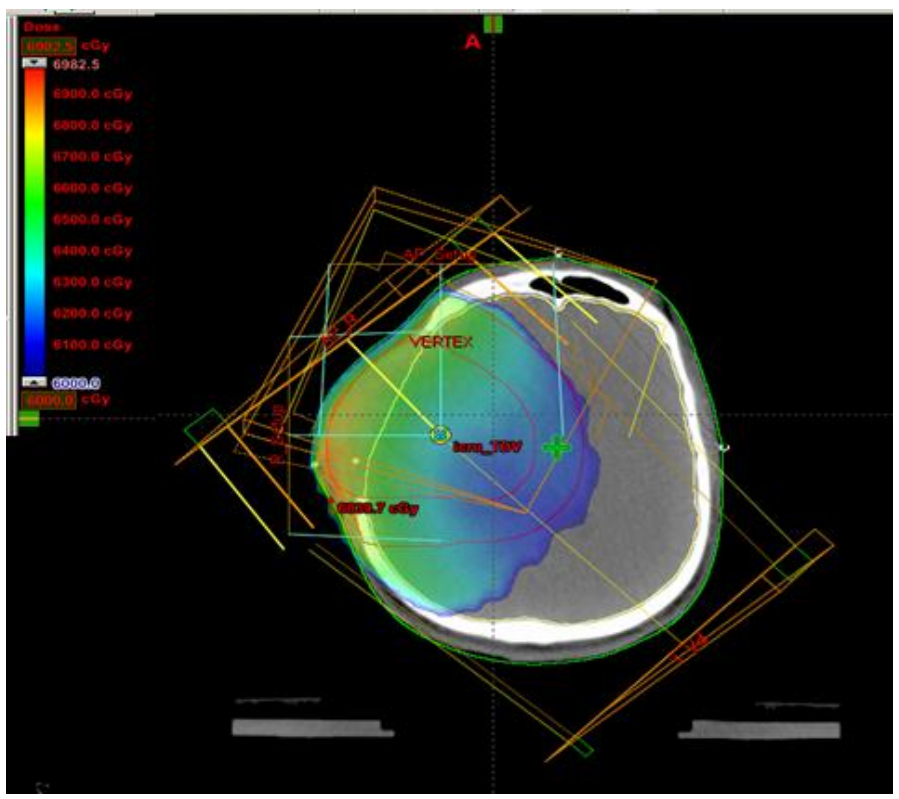

Resim 1. Beyin tümöründe radyoterapi tedavi planı.

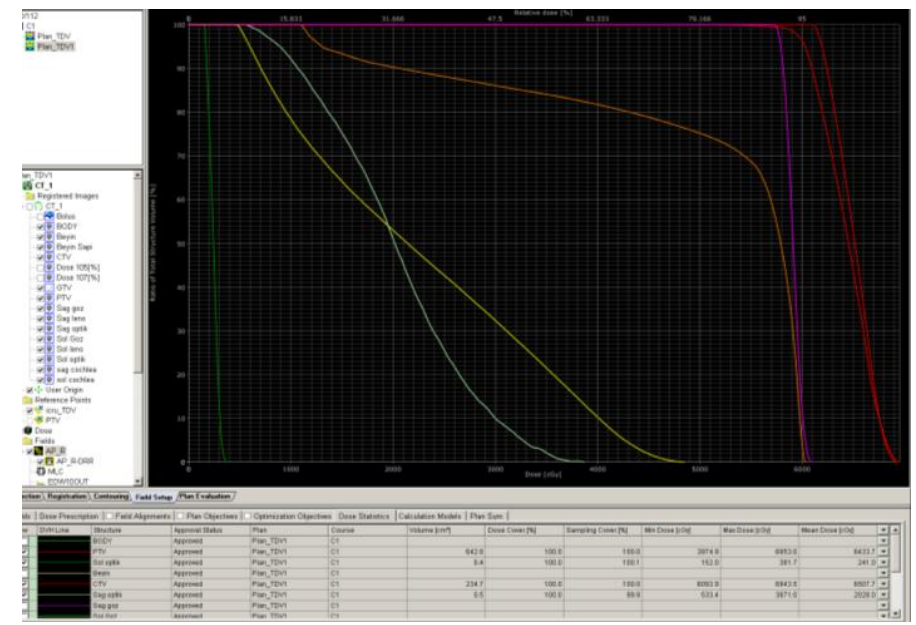




\section{Resim 2. Doz volüm histogramı.}

Tedavi sirasında haftada bir, takiplerde de 3 ayda bir RTOG (Radiotio Therapy Oncology Group) kriterlerine göre yan etki değerlendirilmesi yapıldı.

Analiz için SPSS version 14.0 ile sıklık testleri, ki-kare testi, gruplar arası ortanca değerlerin karşılaştırılması için Mann-Whitney $U$ testi ve Kruskal Wallis testi kullanılırken ikiden fazla gruplar için bonferroni düzeltmesi yapıldı. Sağkalım hızları Kaplan-Meier analizi kullanılarak hesaplandı. Sağkalım üzerine etkili olan bağımsız faktörleri değerlendirmek içinde çok değişkenli analiz (Cox regresyon analizi) yapıldı. P değeri $\leq 0.05$ olması istatistiksel olarak anlamlı kabul edildi. Çalışma öncesinde verilerin toplanması, değerlendirilmesi, analizi ve yorumlanabilmesi için Cumhuriyet Üniversitesi Tıp Fakültesi Etik Kurulu'ndan onay alındı.

\section{Bulgular}

Elli bir (\%67) erkek, 25 (\%33) kadın toplam 76 hasta çalışmaya dahil edildi. Tüm hastalar için ortanca yaş 50 (11-80), erkeklerde 48 (13-80), kadınlarda ise 52 (11-74) olup erkek ve kadınlarda hastalık görülme yaşı bakımından anlamlı fark yoktu (p:0,774). Histopatolojik tanıya göre ortanca yaş değerlendirildiğinde: Düşük gradeli glial tümörlerde ortanca yaş 40 (13-66), yüksek gradeli glial tümörlerde 48 (11-80), glioblastoma multiformede 56 (36-74) idi. Bu üç grup arasında ortanca yaş bakımından istatistiksel olarak fark bulunmaktaydı $(\mathrm{p}: 0,002)$ ve bu fark düşük glial tümör ile glioblastoma multiformeden kaynaklanmaktaydı $(\mathrm{p}<0,001)$.

Hastaların 22'si (\%29) sigara kullanıyordu, 13'ünde (\%17) aile hikayesi, 18'inde de (\%24) komorbidite mevcuttu. Hastaların 54'ünde (\%71) baş ağrısı, 18'inde (\%24) konvüzyon ve 33 'ünde (\%43) bulantı kusma başvuru anında bulunmaktaydı. Histopatolojik olarak: 18 'inde $(\% 24)$ düşük gradeli glial tümör, 17'sinde (\%22) yüksek gradeli glial tümör, 33 'ünde (\%44) glioblastoma multiforme, 4'ünde (\%5) hipofiz adenomu ve 4'ünde (\%5) medullablastom mevcuttu. Hastaların 42'si (\%55) ECOG 0, 22'si (\%46) ECOG 1 ve 12 'si (\%16) ECOG 2 performans durumuna sahipti.

Üç (\%4) hastada grade 1, $15(\% 21)$ hastada grade 2, $14(\% 20)$, hastada grade 3 ve 39 (\%55) hastada grade 4 tümör vardı. Üç (\%4) hastaya sadece cerrahi, 22 (\%29) hastaya cerrahi+radyoterapi, 28 (\%37) hastaya cerrahi+kemoradyoterapi, $9(\% 12)$ hastaya sadece radyoterapi, 9 (\%12) hastaya kemoradyoterapi uygulanırken, $5(\% 6)$ hasta ise tedaviyi kabul etmedi. Cerrahi tedavi olarak 35 (\%46) hastaya subtotal rezeksiyon, 18 (\%24) hastaya total rezeksiyon, 20 (\%26) hastaya sadece biopsi uygulandi, ancak $3(\% 4)$ hastaya radyolojik olarak tanı konuldu. Yüksek gradeli ve glioblastoma multiforme 37 (\%49) hastaya temozolomide ile beraber 60 Gy radyoterapi, düşük gradeli ve subtotal rezeksiyon yapilan, hipofiz adenom ve medullablastoma sahip 31 (\%41) hastaya da $54 \mathrm{~Gy}$ radyoterapi yapılırken, $3(\% 4)$ hastada da tedaviyi tamamlayamadı. Beyin tümörlü hastaların demografik ve klinikopatolojik özellikleri Tablo 1'de gösterilmiştir. Ortanca 16 ay (1-199 ay) takip süresinde, hastaların 30'unda (\%39) ortanca 12 ayda (3-123) nüks gelişti. Düşük gradeli glial tümörlerde ortanca nüks süresi 14 ay (7-123 ay), yüksek gradeli glial tümörlerde ortanca nüks süresi 12 ay (8-52 ay), glioblastoma multiformede ortanca nüks süresi 10 ay (3-38 ay) idi.

Tüm hastalar için ortanca sağkalım 33 ay, hastalıksız ortanca sağkalım 24 ay idi. Ortanca sağkalım, 2 yıllık genel sağkalım, 2 yıllık hastalıksız sağkalım sırasıyla: Düşük gradeli glial tümörlerde 33 ay, $\% 83$ ve $\% 83$, yüksek gradeli glial tümörlerde 12 ay, $\% 46$ ve $\% 40$, glioblastoma multiforme hastalarında 10 ay, $\% 28$ ve $\% 24$ olarak tespit edildi. 
Tablo 1. Beyin tümörlü hastaların demografik ve klinikopatolojik özellikleri.

\begin{tabular}{|c|c|c|c|}
\hline & Ortanca yaş (min-max) & Hasta sayısı (n) & $\%$ \\
\hline \multicolumn{4}{|l|}{ Cinsiyet } \\
\hline Erkek & $48(13-80)$ & 51 & 67 \\
\hline Kadın & $52(11-74)$ & 25 & 33 \\
\hline \multicolumn{4}{|l|}{ Semptomlar } \\
\hline Baş ağrısı & & 54 & 71 \\
\hline Blant1-kusma & & 33 & 43 \\
\hline Konvüzyon & & 18 & 24 \\
\hline \multicolumn{4}{|l|}{ Histopatoloji } \\
\hline Düşük gradeli glial tümör & $40(13-66)$ & 18 & 24 \\
\hline Yüksek gradeli glial tümör & $48(11-80)$ & 17 & 22 \\
\hline Glioblastoma multiforme & $56(36-74)$ & 33 & 44 \\
\hline Hipofiz adenomu & $58(44-70)$ & 4 & 5 \\
\hline Medullablastom & $24(14-44)$ & 4 & 5 \\
\hline \multicolumn{4}{|c|}{ ECOG performans durumu } \\
\hline ECOG0 & & 42 & 55 \\
\hline ECOG1 & & 22 & 46 \\
\hline ECOG2 & & 12 & 16 \\
\hline \multicolumn{4}{|l|}{ Grade } \\
\hline Grade1 & & 3 & 4 \\
\hline Grade2 & & 15 & 21 \\
\hline Grade3 & & 14 & 20 \\
\hline Grade4 & & 39 & 55 \\
\hline \multicolumn{4}{|l|}{ Ki-67 } \\
\hline$\leq 10$ & & 18 & 41 \\
\hline$>10$ & & 26 & 59 \\
\hline \multicolumn{4}{|l|}{ Yerleşim } \\
\hline Frontal lob & & 24 & 32 \\
\hline Pariyetal lob & & 15 & 20 \\
\hline Temporal lob & & 20 & 26 \\
\hline Oksipital lob & & 6 & 8 \\
\hline Diğer & & 11 & 14 \\
\hline \multicolumn{4}{|l|}{ Cerrahi tipi } \\
\hline Biopsi & & 20 & 26 \\
\hline Subtotal eksizyon & & 35 & 46 \\
\hline Total eksizyon & & 18 & 24 \\
\hline \multicolumn{4}{|l|}{ Tedavi } \\
\hline Cerrahi & & 3 & 4 \\
\hline $\mathrm{RT}^{*}$ & & 9 & 12 \\
\hline $\mathrm{KRT}^{* *}$ & & 9 & 12 \\
\hline Cerrahi+RT & & 22 & 29 \\
\hline Cerrahi+KRT & & 28 & 37 \\
\hline
\end{tabular}

Tek değişkenli analizde hastaların genel sağkalımını, histopatoloji $(<0,001)$, grade (p:0,003), yaş $(\leq 50$ ve $>50, p:<0,001)$, Ki-67 değeri $(\leq 10$ ve $>10, p: 0,019)$, ECOG performans durumu (p:0,006) etkiledi. Cinsiyet (p:0,591) ve cerrahi tipi (biopsi, subtotal rezeksiyon ve total rezeksiyon, p:0,140) istatistiksel olarak hastaların genel sağkalımını etkilememekteydi. Ancak biopsi ile total rezeksiyon karşılaştırıldığında sağkalım istatiksel olarak anlamlı etkilendi (p:0,017). Çok değişkenli analizde ise grade (p:0,013), yaş (p:0,025) ve ECOG performans durumu (p:0,006) sağkalımı bağımsız olarak etkileyen prognostik faktörlerdi. Sırasıyla, yüksek gradeli tümörlerde 3,84 kat, yaşlı hastalarda 2,20 kat, ECOG2 performans durumuna sahip hastalarda 1,91 kat sağkalımın daha kötü etkilendiği görüldü. Tablo 2 'de tek değişkenli ve çok değişkenli sağkalım analizleri görülmektedir. 
Tablo 2. Tek değişkenli ve çok değişkenli analizlerin sonuçları.

\begin{tabular}{|c|c|c|c|c|c|}
\hline \multicolumn{6}{|c|}{ Tek değişkenli analiz } \\
\hline & $\begin{array}{l}\text { Hasta sayıs1 } \\
(\%)\end{array}$ & $\begin{array}{l}2 \text { yıllık genel } \\
\text { sağkalım (\%) }\end{array}$ & p değeri & $\begin{array}{l}2 \text { yıllık hastalıksız } \\
\text { sağkalım }(\%)\end{array}$ & $\mathrm{p}$ değeri \\
\hline \multicolumn{6}{|l|}{ Cinsiyet } \\
\hline Erkek & & 55 & \multirow[t]{2}{*}{0,591} & 55 & 0,066 \\
\hline Kadın & & 58 & & 48 & \\
\hline \multicolumn{6}{|l|}{ Yaş } \\
\hline$\leq 50$ & 40 & 69 & \multirow[t]{2}{*}{$<0,001$} & 65 & 0,001 \\
\hline$>50$ & 36 & 34 & & 34 & \\
\hline \multicolumn{6}{|l|}{ Histopatoloji } \\
\hline Düşük gradeli glial tümör & $18(24)$ & 83 & \multirow[t]{3}{*}{$<0,001$} & 83 & $<0,001$ \\
\hline Yüksek gradeli glial tümör & $17(22)$ & 46 & & 40 & \\
\hline Glioblastoma multiforme & $33(43)$ & 28 & & 24 & \\
\hline \multicolumn{6}{|l|}{ Cerrahi tipi } \\
\hline Biopsi & $20(26)$ & 37 & \multirow[t]{3}{*}{0,140} & 37 & 0,268 \\
\hline Subtotal eksizyon & $35(46)$ & 50 & & 45 & \\
\hline Total eksizyon & $18(24)$ & 71 & & 71 & \\
\hline \multicolumn{6}{|c|}{ ECOG performans durumu } \\
\hline ECOG 0 & $42(55)$ & 65 & \multirow[t]{3}{*}{0,006} & 60 & 0,023 \\
\hline ECOG 1 & $22(29)$ & 45 & & 45 & \\
\hline ECOG 2 & $12(16)$ & 25 & & 25 & \\
\hline \multicolumn{6}{|l|}{ Grade } \\
\hline Grade $1-2$ & $18(25)$ & 83 & \multirow[t]{2}{*}{$<0,001$} & 83 & $<0,001$ \\
\hline Grade 3-4 & $53(75)$ & 37 & & 33 & \\
\hline \multicolumn{6}{|l|}{ Ki-67 } \\
\hline$\leq 10$ & $18(41)$ & 72 & \multirow[t]{2}{*}{0,016} & 71 & 0,019 \\
\hline$>10$ & $26(59)$ & 38 & & 31 & \\
\hline \multicolumn{6}{|c|}{ Çok değişkenli analiz } \\
\hline & p değeri & $\operatorname{Exp}(B$ & $\% 9$ & güven aralığı & \\
\hline Grade (1-2 ve 3-4) & 0,013 & 6,84 & 1,33 & $-11,06$ & \\
\hline ECOG performans durumu & 0,006 & 1,91 & & $-3,01$ & \\
\hline Yaş $(\leq 50$ ve $>50)$ & 0,025 & 2,20 & 1,11 & $-4,36$ & \\
\hline
\end{tabular}

Tedaviye bağlı akut yan etki: $2(\% 3)$ hastada nötropeni, $11(\% 14)$ hastada trombositopeni, $9(\% 12)$ hastada anemi, $32(\% 42)$ hastada bulantı-kusma, 14 (\%18) hastada mukozit, 51 (\%67) hastada baş ağrısı, 14 (\%18) hastada antiepileptiklere bağlı ilaç reaksiyonu, 15 (\%20) hastada baş dönmesi görüldü. Geç yan etki olarak $3(\% 5)$ hastada radyoterapi nekrozu saptandi. Radyoterapi nekrozu diffüzyon MRI (magnetik resonans) ile teşhis edildi. Radyoterapi nekrozu gelişen 3 hastanın radyoterapi dozu 60 Gy idi. Radyoterapi ve kemoradyoterapi uygulamalarında yan etki bakımından sadece trombositopeni de fark bulunmaktaydı (p:0,045). Tablo 3'de radyoterapi ve kemoradyoterapiye bağlı yan etkilerin karşılaştırılması görülmektedir.

Tablo 3. Radyoterapi ve kemoradyoterapinin yan etkilerinin karşıılaştırılması.

\begin{tabular}{lllll}
\hline \multicolumn{5}{c}{ Akut yan etki } \\
& Radyoterapi n (\%) & Kemoradyoterapin (\%) & Toplam (\%) & p değeri \\
\hline Nötropeni & $1(3)$ & $1(3)$ & $2(3)$ & 0,708 \\
Trombositopeni & $2(7)$ & $9(24)$ & $11(14)$ & 0,045 \\
Anemi & $3(10)$ & $6(16)$ & $9(12)$ & 0,336 \\
Bulantı-kusma & $13(42)$ & $19(51)$ & $32(42)$ & 0,298 \\
Baş ağrisı & $20(65)$ & $31(84)$ & $51(67)$ & 0,061 \\
Baş dönmesi & $8(26)$ & $7(19)$ & $15(20)$ & 0,346 \\
Mukozit & $6(19)$ & $8(21)$ & $14(18)$ & 0,530 \\
\hline \multicolumn{5}{l}{} \\
\hline Radyoterapi nekrozu & $2(7)$ & Geç yan etki & \\
\hline
\end{tabular}




\section{Tartışma}

Beyin tümörleri, yerleşimin yerinin hayati fonksiyonlarına sahip olması, bölgenin dar olması nedeniyle hasta yaşamını ve hayat kalitesini son derece kötü etkileyen tümörlerdir. Primer beyin tümörlerinin sinıflaması histolojik karakterlerine ve lokalizasyonlarına, invazyon veya malignitesine göre yapılmaktadır. Tümörlerin invazyon derecesi tümör gradi ile belirtilmektedir. The Central Brain Tumor Registry of the United States (CBTRUS) verilerine göre tüm beyin tümörlerinde tanıda ortalama yaş 53, glioblastoma multiforme ve meningioma da 62, düşük gradeli glial tümörlerde ise 37 olarak belirtilmiştir [7]. Bu çalışmada, tüm hastalarda ortanca yaş 50 idi ve erkek (48 yaş) kadın (52 yaş) ortanca yaş bakımından fark bulunmamaktaydı. Histolojik tiplere göre ortanca yaş: glioblastoma multiformede 56, düşük gradeli tümörlerde 40 olup CBTRUS verileri ile benzerlik göstermekteydi. Ancak glioblastoma multiformeli hastalarımızın yaşı biraz daha gençti. CBTRUS verilerine göre düşük glial tümörlerin görülme sıklığı \%30-40 [7]. SEER 1973-1991 verilerine göre en s1k görülen beyin tümörü \% 41,9 astrositom (grade II astrositom ve anaplastik astrositom) ve \%40,1 glioblastoma multiformedir [3]. Çalışmamızda düşük gradeli glial tümörler $\% 26$, yüksek gradeli glial tümörler $\% 22$, glioblastoma multiforme $\% 43$, diğer tümörler de $\% 11$ oranında görüldü. Sonuçlar literatürdeki veriler ile uyumlu idi. Curan ve ark. [8]'ları yüksek gradeli glial tümörlerde 50 yaş ve üzeri hastalarda sağkalımı olumsuz etkilediğini bildirmişlerdir. Tanı anında hasta yaşı, astrositomalar ve oligodendrogliomalarda önemli prognostik parametredir. Yapılan çalışmalarda ileri yaştaki hastalarda tümör proliferasyon indeksinin daha yüksek olduğu bildirilmiştir $[9,10]$. Proliferasyon indeksi ile histolojik grade arasında da benzer ilişki gösterilmiştir [9]. Klinik olarak yüksek gradeli tümörlerin görülme yaşı düşük gradeli tümörlere göre daha ileridir. Çalışmamızda da verilere benzer olarak en agresif davranışa sahip olan glioblastoma multiformeli hastaların yaşları da, diğer histopatolojik tiplere göre daha fazlaydı. Elli yaş üzeri hastalarda, tek değişkenli sağkalım analizinde sağkalım daha genç hastalara göre olumsuz etkilenmekteydi. Çok değişkenli analizde ise 50 yaş üzeri hastaların sağkalımı 2,20 kat daha kötü etkilendi. İki yıllık genel sağkalım ve 2 yıllık hastalıksız sağkalım, $\leq 50$ yaşındaki hasta grubunda $\% 69$ ve $\% 65,>50$ yaşındaki hasta grubunda \%34 ve \%34 tespit edildi. European Organization for Research and Treatment of Cancer (EORTC) düşük gradeli glial tümörlerin radyoterapi doz karşılaştırması yapan çalışmalarında (45 Gy'e karşı 59.4 Gy), 2 ve 5 yıllık genel sağkalımı sırasıyla düşük doz kolunda $\% 94$ ve $\% 72$, yüksek dozda $\% 85$ ve $\% 64$, yan etki bakımından ise, 5 yılda grade 3 ve 4 toksisite görülme oranını düşük dozda $\% 2$, yüksek dozda \%10 olarak bildirmişlerdir [11]. Stupp ve ark. [6]'ları 573 glioblastoma multiformeli hastalar ile yaptığı çalışmada postoperatif tek başına radyoterapi ve temozolomide ile eş zamanlı kemoradyoterapinin sağkalıma olumlu etkisinin göstermiştir. Bu çalışmada ortanca 28 ay takipte, ortanca sağkalım radyoterapi kolunda 12,1 ay, kemoradyoterapide 14,6 ay; 2 y1llık genel sağkalım ise radyoterapi kolunda $\% 10,4$, kemoradyoterapi kolunda \%26,5 olarak tespit edilmiştir. Çalışmamızda, tümörün histopatolojisi sağkalımı, tek değişkenli analizde etkilemiştir. Düşük gradeli glial tümörlerde 2 yıllık genel sağkalım \%83, 2 yıllık hastalıksız sağkalım ise \%83 idi. İki y1llık genel sağkalım ve 2 yıllık hastalıksız sağkalım sırasıyla,yüksek gradeli glial tümörlerde $\% 46$ ve $\% 40$, glioblastoma multiforme de $\% 28$ ve $\% 24$ olarak tespit edildi. Düşük gradeli glial tümörlü hastaların sağkalım sonuçları EORTC sonuçlarına göre biraz düşük, ancak glioblastoma multiformeli hastaların sonuçları benzerlik göstermektedir. Histopatolojik derece, yani gradin prognostik önemi pek çok çalışmada gösterilmiştir [12, 13]. Bozdoğan ve ark. [14]'ları 100 glial tümörlü hastada yaptıkları çalışmada hastalık gradi ve Ki-67 değerlerinin arttıkça sağkalımın azaldığını bildirmişlerdir. Çalışmamızda, hastalık gradi arttıkça 2 yıllık genel sağkalım ve 2 yıllık hastalıksız sağkalımın azaldığ görüldü ve tek değişkenli analizde fark istatiksel olarak anlamlı bulundu. Çok değişkenli analizde ise, yüksek gradeli tümörlerde sağkalım düşük gradeli tümörlere göre 3,84 kat daha kötü etkilendiği görüldü. 
Hastaların performans durumu çoğu tümörlerde olduğu gibi beyin tümörlerinde de sağkalım ile ilişkilidir. Bir çok çalışmada da kötü performans durumuna sahip hastaların sağkalımının daha kötü etkilendiği gösterilmiştir [6, 15, 16]. Chang ve ark. [15]'ları 18 aylık sağkalımı KPS 70 ve üzeri hastalarda \%34, KPS 70 altı hastalarda ise \%13 olarak raporlamışlardır. Beyin tümörleri ile yapılan çalışmaların çoğunda hastanın performans durumunu KPS (Karnovsky Performance Status) ile değerlendirilmiştir. Çalışmamızda KPS yerine ECOG performans durumunu kullanıldı. ECOG performans durumu, KPS gibi kötüleştikçe hastaların sağkalımı daha kötü etkilemekteydi. Hastaların ECOG performans durumu ile sağkalım arasında, hem tek değişkenli analizde hem de çok değişkenli analizde istatistiksel olarak anlamlı ilişkili bulunmaktaydı. ECOG2 performans durumuna sahip hastaların sağkalımı, ECOG0 performans durumuna sahip hastaların sağkalımına göre 1,91 kat daha kötü etkilendi. Ki-67 hücre proliferasyon aktivitesini ölçmede beyin tümörlerinin birçoğunda çalışılmış ve anlamlı sonuçlar çıkmıştır $[9,17$, 18]. Kılıçoğlu ve ark. [18]'ları 58 ependimomaya sahip hastalarda yaptıkları çalışmada, grade ve sellülarite ile Ki-67 ekspresyonu arasında istatistiksel olarak korelasyon olduğunu bildirmişlerdir. Çalışmamızda Ki-67 değerini $\leq 10$ ve $>10$ strafiye edildiğinde; 2 yıllık genel sağkalım ve 2 yıllık hastalıksız sağkalım sırasıyla Ki-67 değeri $\leq 10$ olan hastalarda $\% 72$ ve $\% 71$, Ki-67 değeri $>10$ olan hastalarda ise $\% 38$ ve $\% 31$ olup aradaki fark istatistiksel olarak anlamlıydı. Ancak çok değişkenli analizde bağımsız prognostik faktör değildi. Yapılan çalışmalarda cerrahi rezeksiyonun önemli bir prognostik faktör olduğu gösterilmiştir $[19,20]$. RTOG'un yaptığı 3 çalışmanın analizinde, özellikle sadece biopsi yapılan hastalarda sağkalımın total rezeksiyona göre daha kötü etkilendiği raporlanmıştır [20]. Bu analizde tama yakın rezeksiyon yapılan hastalarda ortanca sağkalım 11,3 ay iken biopsi yapılan hastalarda 6,6 ay olarak saptanmıştır. Ancak çalışmamızda biopsi, subtotal ve total rezeksiyon yapılan gruplar arasında sağkalım farkı istatistiksel olarak anlamlı değildi. Biopsi uygulanan hastalar ile total rezeksiyon yapılan hastalar karşılaştırıldığında ise sağkalım farkı anlamlıydı. İki yıllık gene sağkalım biopsi yapılan hastalarda \%37, subtotal rezeksiyon yapılanlarda \%50, total rezeksiyon yapılanlarda \%71 olarak tespit edildi. Düşük gradeli glial tümörler için EORTC, anaplastik astrositom ve glioblastoma multiformeli hastalar için RTOG sağkalımı predikte eden gruplar tanımlamışlardır. EORTC düşük gradeli glial tümörlerde, yaş $(<40$ ve $\geq 40$ ), tümörün en geniş çapı $(<6 \mathrm{~cm}$ ve $\geq 6 \mathrm{~cm}$ ), tümörün orta hattaki durumu (geçmiş ve geçmemiş), histopatolojik tip (oligodendrogliom veya mikst tipe karşı astrositom), preoperatif nörolojik defisitin varlığı (yok ve var) ile sağkalımı predikte eden skorlama sistemini geliştirmişlerdir [21]. RTOG malign astrositom ve glioblastomada geniş bir hasta serisinde (1578 hasta), histoloji, hasta yaşı, performans durumu gibi prognostik faktörlerden RPA (recursive-partioning analysis-tekrarlayan bölünme analizi) ile 6 risk grubu belirlemişlerdir. Bu risk gruplarında hasta yaşı ( $<50$ ve $\geq 50$ yaş), KPS ( $\geq 90$ ve $<90$, $\geq 70$ ve $<70$ ), histopatoloji (anaplastik astrositom ve glioblastoma multiforme), hastanın mental durumu (normal veya anormal) ve semptomların başlama süresi ( 3 aydan az veya fazla) kullanılmıştır. Gruplara arasında sağkalım \%4-76 arasında değişmektedir [8]. Çalışmamızda, hasta yaşı, grade, histopatoloji, ECOG performans durumu, Ki-67 değeri sağkalımı istatistiksel olarak anlamlı etkileyen prognostik faktörlerdi. Bağımsız prognostik faktörler ise grade, yaş ve ECOG performans durumu idi. Uzun dönem takip edilen beyin tümörlü hastalarda en korkulan geç yan etki radyoterapi nekrozudur. Beyine 180 cGy fraksiyon ile uygulanan toplam 4500-6000 cGy radyoterapi dozunda, klinik olarak kabul edilebilir yan etki insidans1 \%3-5'dir [22]. Literatürde radyoterapi nekrozu en yüksek \%24 oranında bildirilmiştir [23]. Çalışmamızda diffüz MRI ile $3(\% 5)$ hastada radyoterapi nekrozu tespit edildi. Akut yan etkiler genellikle kortikosteroid ile kontrol altına alındı. Kemoradyoterapi gören hastaların akut yan etkileri tek başına radyoterapi alan hastalarla benzerdi, ancak trombositopeni kemoradyoterapi alan hastalarda daha fazla rastlandı ve aradaki fark istatistiksel olarak anlamlı bulundu. Genel olarak temozolomide ile eş zamanlı radyoterapi hastalar tarafından iyi tolere edildi. 
Sonuç olarak; çalışmamızda düşük gradeli glial tümörler haricinde yüksek gradeli glial tümör ve glioblastoma multiformede 2 yıllık genel sağkalım literatür ile benzerdi. Hasta yaşı, grade, hastaların performans durumu sağkalımı etkileyen en önemli prognostik faktörlerdi. Kemoradyoterapi ve tek başına radyoterapinin yan etkileri trombositopeni hariç birbirine benzer bulundu.

\section{Kaynaklar}

1. Jemal A, Murray T, Ward E, Samuels A, Tiwari RC, Ghafoor A, Feuer EJ, Thun MJ. Cancer statistics, 2005. CA Cancer J Clin 2005; 55: 10-30.

2. Shaw EG, Debinski W, Robbins ME. Central nervous system tumors. Gunderson LL, Tepper JE (ed.) Clinical Radiation Oncology (2th.). Elsevier, Philadelphia 2007; 2: 459-91.

3. Davis FG, Freels S, Grutsch J, Barlas S, Brem S. Survival rates in patients with primary malignant brain tumors stratified by patient age and tumor histological type: an analysis based on Surveillance, Epidemiology, and End Results (SEER) data, 1973-1991. J Neurosurg 1998; 88: 1-10.

4. Siker ML, Donahue BR, Vogelbaum MA, Tome WA, GilbertMR, Mehta MP. Primary Intracranial Neoplasms. Halperin EC, Perez CA, Brady LW (ed.). Principles and Practice of Radiation Oncology (5th). Lippincott Williams \& Wilkins, Philadelphia 2008: 32: 717-49.

5. Davis FG, McCarthy BJ, Freels S, Kupelian V, Bondy ML. The conditional probability of survival of patients with primary malignant brain tumors: surveillance, epidemiology, and end results (SEER) data. Cancer 1999; 85: 48591.

6. Hegi ME, Diserens AC, Gorlia T, Hamou MF, de Tribolet N, Weller M, Kros JM, Hainfellner JA, Mason W, Mariani L, Bromberg JE, Hau P, Mirimanoff RO, Cairncross JG, Janzer RC, Stupp R. MGMT gene silencing and benefit from temozolomide in glioblastoma. N Engl J Med 2005; 352: 997-1003.

7. Central Brain Tumor Registry of the United States. Statistical Report: Primary Brain Tumors in the United States, 1998-2002. Hinsdale, IL: CBTRUS; 2005. Available at: http://www.cbtrus.org/reports/reports.html (Erişim tarihi: 03.09.2012)

8. Curran WJ Jr, Scott CB, Horton J, Nelson JS, Weinstein AS, Fischbach AJ, Chang CH, Rotman M, Asbell SO, Krisch RE, Nelson DF.. Recursive partitioning analysis of prognostic factors in three Radiation Therapy Oncology Group malignant glioma trials. J Natl Cancer Inst 1993; 85: 704-10.

9. Coons SW, Johnson PC, Pearl DK. The prognostic significance of Ki-67 labeling indices for oligodendrogliomas. Neurosurgery 1997; 41: 878-85.

10. McGuire CS, Sainani KL, Fisher PG. Both Location and Age Predict Survival in Ependymoma: A SEER Study. Pediatr Blood Cancer 2009; 52: 65-9.

11. Karim AB, Maat B, Hatlevoll R, Menten J, Rutten EH, Thomas DG, Mascarenhas F, Horiot JC, Parvinen LM, van Reijn M, Jager JJ, Fabrini MG, van Alphen AM, Hamers HP, Gaspar L, Noordman E, Pierart M, van Glabbeke M. A randomized trial on dose-response in radiation therapy of low-grade cerebral glioma: European Organization for Research and Treatment of Cancer (EORTC) Study 22844. Int J Radiat Oncol Biol Phys 1996; 36: 549-56.

12. Macdonald DR. Low-grade gliomas, mixed gliomas, and oligodendrogliomas. Semin Oncol 1994; 21: 236-48.

13. Bruner JM. Neuropathology of malignant gliomas. Semin Oncol 1994; 21: 12638.

14. Bozdoğan N, Erden E, Atasoy P, Tun K, Savaş A. Glial tümörlerde proliferasyon markerlerinin prognostik önemi. Türk Nöroşirürji Dergisi 2000; 10: 11-5.

15. Chang CH, Horton J, Schoenfeld D, Salazer O, Perez-Tamayo R, Kramer S, 
Weinstein A, Nelson JS, Tsukada Y. Comparison of postoperative radiotherapy and combined postoperative radiotherapy and chemotherapy in the multidisciplinary management of malignant gliomas. A joint Radiation Therapy Oncology Group and Eastern Cooperative Oncology Group study. Cancer 1983; 52: 997-1007.

16. Hulshof MC, Schimmel EC, Andries Bosch D, González González D. Hypofractionation in glioblastoma multiforme. Radiother Oncol 2000; 54: 143-8.

17. Karamitopoulou E, Perentes E, Diamantis I, Maraziotis T. Ki-67 immunoreactivity in human central nervous system tumors: a study with MIB 1 monoclonal antibody on archival material. Acta Neuropathol 1994; 87: 47-54.

18. Kılıçoğlu MK, Tolunay Ş, Ferik Z, Elezoğlu B, Aşık N, Korfalı E, Bekar A, Kocaeli H, Taşkapılıoğlu Ö. Epandimomlarda Ki-67 ekspresyonunun histopatolojik parametreler ile ilişkisi. Uludağ Üniversitesi Tıp Fakültesi Dergisi 2011; 37: 93-7.

19. Burger PC, Scheithauer BW, Vogel FS. Surgical pathology of the nervous system and its coverings. 4th edition. Philadelphia: Churchill Livingstone; 2002; 241-54.

20. Simpson JR, Horton J, Scott C, Curran WJ, Rubin P, Fischbach J, Isaacson S, Rotman M, Asbell SO, Nelson JS, Weinstein AS, Nelson DF. Influence of location and extent of surgical resection on survival of patients with glioblastoma multiforme: Results of three consecutive Radiation Therapy Oncology Group (RTOG) clinical trials. Int J Radiat Oncol Biol Phys 1993; 26: 239-44.

21. Pignatti F, van den Bent M, Curran D, Debruyne C, Sylvester R, Therasse P, Afra D, Cornu P, Bolla M, Vecht C, Karim AB; European Organization for Research and Treatment of Cancer Brain Tumor Cooperative Group; European Organization for Research and Treatment of Cancer Radiotherapy Cooperative Group. Prognostic factors for survival in adult patients with cerebral low-grade glioma. J Clin Oncol 2002; 20: 2076-84.

22. Safdari H, Fuentes JM, Dubois JB, Alirezai M, Castan P, Vlahovitch B. Radiation necrosis of the brain: Time of onset and incidence related to total dose and fractionation of radiation. Neuroradiology 1985; 27: 44-7.

23. Kumar AJ, Leeds NE, Fuller GN, Van Tassel P, Maor MH, Sawaya RE, Levin VA. Malignant gliomas: MR imaging spectrum of radiation therapy- and chemotherapy-induced necrosis of the brain after treatment. Radiology 2000; 217: 377-84. 